\title{
Correction: A novel UBE2T inhibitor suppresses Wnt/ $\beta$-catenin signaling hyperactivation and gastric cancer progression by blocking RACK1 ubiquitination
}

\author{
Zeyuan Yu - Xiangyan Jiang - Long Qin · Haixiao Deng • Jianli Wang • Wen Ren · Hongbin Li - Lei Zhao • \\ Huanxiang Liu · Hong Yan - Wengui Shi - Qi Wang · Changjiang Luo - Bo Long · Huinian Zhou - Hui Sun • \\ Zuoyi Jiao (i)
}

Published online: 11 March 2021

(c) The Author(s) 2021. This article is published with open access

\section{Correction to: Oncogene \\ https://doi.org/10.1038/s41388-020-01572-w}

The original version of this article unfortunately contained a mistake. In Fig. 6D, the abscissa should be "concentration $[\mu \mathrm{M}]$ " and in the figure caption of Fig. 6D, the concentration range should be given as " $31 \mathrm{nM}$ to $500 \mu \mathrm{M}$ ". The corrected figure and figure caption is given below. The original article has been corrected.
Open Access This article is licensed under a Creative Commons Attribution 4.0 International License, which permits use, sharing, adaptation, distribution and reproduction in any medium or format, as long as you give appropriate credit to the original author(s) and the source, provide a link to the Creative Commons license, and indicate if changes were made. The images or other third party material in this article are included in the article's Creative Commons license, unless indicated otherwise in a credit line to the material. If material is not included in the article's Creative Commons license and your intended use is not permitted by statutory regulation or exceeds the permitted use, you will need to obtain permission directly from the copyright holder. To view a copy of this license, visit http://creativecommons.org/licenses/by/4.0/. 
A
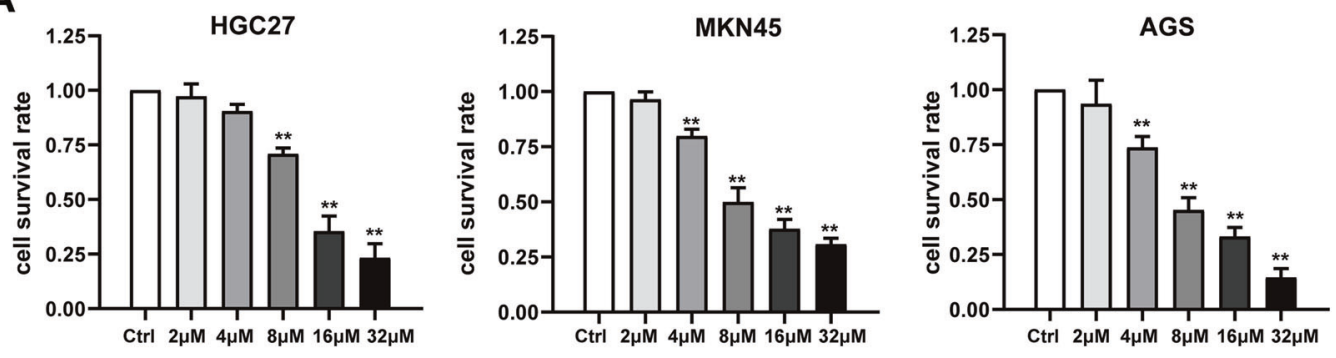

B

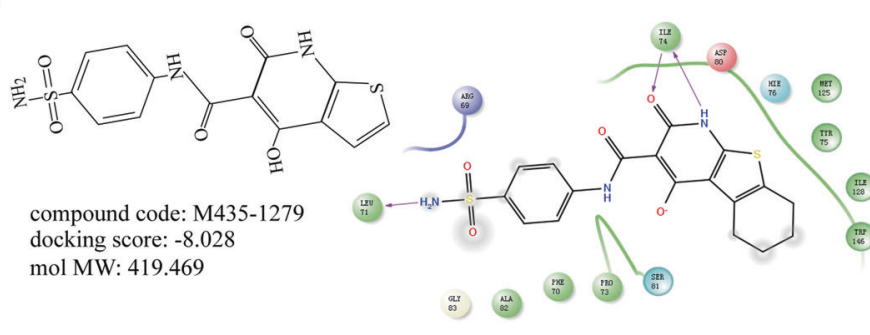

C

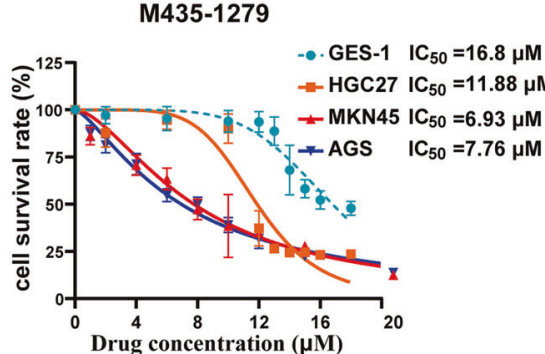

D

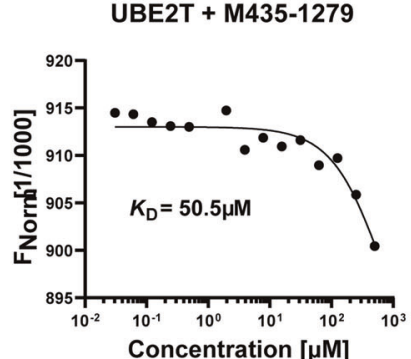

\begin{tabular}{lc}
\multicolumn{2}{c}{ Toxicity Prediction } \\
\hline Characteristic & Value \\
\hline ALogP & 1.334 \\
Hydrogen-bond donor & 4 \\
Hydrogen-bond receptor & 5 \\
Mutagenicity (Ames) & No \\
Carcinogenicity & No \\
LD50 & $15.6 \mathrm{~g} / \mathrm{kg}$ \\
EC50 & $7.47 \mathrm{mg} / \mathrm{L}$ \\
LOAEL & $0.207 \mathrm{~g} / \mathrm{kg}$ \\
\hline
\end{tabular}

Fig. 6 Identification of UBE2T inhibitor. A Cell survival rate of HGC27, AGS, and MKN45 cells after 48 h treated with M435-1279. Cell viability was detected by 3-(4,5-dimethyl-2-thiazolyl)-2,5-diphenyl-2-H-tetrazolium bromide (MTT) assay. One-way analysis of variance (ANOVA) was used to examine statistical significance (mean \pm S.D., $n=6, * * P<0.01, * P<0.05$ ). B A simulation snapshot of M435-1279 with the allosteric site of UBE2T by molecular dynamics simulations. Sticks defined as the compounds and the active sites interacted with UBE2T, red thread dotted lines defined as hydrogen bonds between the compounds and UBE2T. For the compound, hydrogen: white, carbon: blue, oxygen: red, nitrogen: dark blue, and sulfur: yellow. C The effect of M435-1279 on the growth of HGC27, AGS, MKN45, and GES-1 (as control), respectively. Cell viability was detected by 3-(4,5-dimethyl-2-thiazolyl)-2,5-diphenyl-2-H-tetrazolium bromide (MTT) assay. D The binding of fluorescently labeled UBE2T to M435-1279 is analyzed with microscale thermophoresis (MST) assay. The M435-1279 is titrated from $31 \mathrm{nM}$ to $500 \mu \mathrm{M}$. The change in the thermophoretic signal leads to a $\mathrm{Kd}=50.5 \mu \mathrm{M}$. E The toxicity of M435-1279 is predicted based on TOPKAT analysis. ALogP lipophilicity ( $<5$ value shows good lipophilicity), LD50 50\% lethal dose of a chemical that kills 50\% of a sample population, EC50 water flea EC50, 50\% effective concentration, LOAEL lowest-observed-adverse-effect level. 